\title{
Does the Interplay of Callous-Unemotional Traits and Moral Disengagement Underpin Disruptive Behavior? A Systematic Review
}

This article was published in the following Dove Press journal: Adolescent Health, Medicine and Therapeutics

\author{
Marinella Paciello' \\ Giulia Ballarotto ${ }^{2}$ \\ Luca Cerniglia (D' \\ Pietro Muratori ${ }^{3}$ \\ 'Faculty of Psychology, Uninettuno \\ Telematic International University, Rome, \\ Italy; ${ }^{2}$ Department of Dynamic and \\ Clinical Psychology, "Sapienza" \\ University, Rome, Italy; ${ }^{3}$ IRCCS \\ Fondazione Stella Maris, Scientific, \\ Institute of Child Neurology and \\ Psychiatry, Calambrone, Pisa, Italy
}

Correspondence: Marinella Paciello Faculty of Psychology, Uninettuno Telematic International University, Corso Vittorio Emanule II, Rome 39 00I86, Italy Email m.paciello@uninettunouniversity.net

\begin{abstract}
Disruptive behavior could represent an (un)moral behavioral component of multidimensional construct of morality that includes affective and cognitive aspects. Thus, it is pivotal to investigate their interplay between affective and cognitive processes the better to understand how to intervene to contrast disruptive behavior and its antisocial outcomes. The present review has examined the relationship between affective and cognitive processes implied in moral functioning by focusing on callous-unemotional traits (CU) and moral disengagement. Starting from 1005 records identified by PsycINFO, Pubmed, and Pubpsych, only 13 studies have been selected. These studies show different theoretical approaches and methodologies and put in evidence the nuances of possible interactions of CU and moral disengagement during adolescence based on different research field. Overall, most of the scholars seem to conclude that different interplay can be plausible, suggesting that it is likely that during the adolescence the influence of moral disengagement and $\mathrm{CU}$ is reciprocal and longitudinal. Specifically, in adolescents with Disruptive Behavior Disorders CU and moral disengagement can move together in organizing and becoming chronic of antisocial affective-cognitive system, and in particular moral disengagement may give a free way to engage in disruptive behavior.
\end{abstract}

Keywords: disruptive behavior, callous-unemotional traits, moral disengagement, adolescence, morality

\section{Introduction}

Disruptive Behavior Disorders (DBDs) are among the most prevalent juvenile psychopathological problems ${ }^{1}$ and represent a common reason for children and adolescents' referrals to mental health clinics. ${ }^{2}$ Adolescents with DBDs could show a broad and heterogeneous range of harmful behaviors, such as aggressive conduct (e.g., assaulting, bullying, being cruel), cover status offences (breaking rules, swearing) property violations (vandalizing, stealing, setting fire), and oppositional overt behaviors (angry-resentful, annoying others, defying adults' requests). ${ }^{3}$ The persistence of these severe behavioral problems from childhood to late adolescence is associated with psychosocial impairment, poor diagnosis, and antisocial outcomes, ${ }^{4}$ and also with anti-social personality disorder in adulthood. ${ }^{5}$ Thus, a large number of researchers have explored the possible multiple risk factors that could foster the crystalizing of disruptive behaviors over the course of development.

Overall, recent literature suggested that children more at risk to persevere in disruptive behaviors are mainly characterized, at an individual level, by difficulties 
related to both moral emotions (e.g., lack of empathy and scarce of sense of guilt), and moral cognition (e.g., weak moral judgment and low personal responsibility). ${ }^{6,7}$ Disruptive behavior could represent an (un)moral behavioral component of multi-dimensional construct of morality that includes affective and cognitive aspects. ${ }^{8}$ Specifically, while affective morality refers to affective processes that allow establishing authentic and empathic relationships with others, cognitive morality refers to cognitive processes that allow regulating the moral behavior in social interactions. Within a personality psychology framework, both these processes are related to (un)moral functioning and behavior and could crystallize into stable cognitive-affective structure over the course of the development. Thus, it is pivotal to investigate their interplay between affective and cognitive processes the better to understand how to intervene to contrast disruptive behavior and its antisocial outcomes, such as antisocial personality disorders. Despite scholars from different fields have suggested the opportunity to understand how affective and cognitive moral dimensions jointly operate in explaining moral conduct, ${ }^{9}$ only few studies have investigated their relationship in relation to disruptive behavior during adolescence specifically.

The present review will exam the relationship between affective and cognitive processes implied in moral functioning by focusing on callous-unemotional traits (CU) and moral disengagement, two well-known aggression-related individual dimensions. $\mathrm{CU}$ refers to the lack of empathy and guilt, as well as shallow emotions ${ }^{10}$ and moral disengagement can be defined as a self-serving cognitive distortion aimed at "normalizing" antisocial, wrongful, and harmful behaviors. Recent studies have suggested a possible inter-relationship between $\mathrm{CU}$ and moral disengagement in explaining aggressive and disruptive conducts, ${ }^{11-15}$ but results are preliminary and not conclusive. Indeed, scholars have suggested different hypotheses that will be exposed below in this manuscript. In addition, some differences in the findings may be due to the specific population examined (i.e., clinical or community sample) and the types of aggressive and antisocial behaviors investigated. ${ }^{16} \mathrm{It}$ is noteworthy that these two dimensions have been studied by different branches of literature in clinically-, developmentally-, and criminologically-oriented research. Overall, to date, the relationship between $\mathrm{CU}$ and moral disengagement is still controversial and needs clarification because this would allow understanding how affective processes, rooted on biological bases, ${ }^{17,18}$ and cognitive processes, learned within social interactions ${ }^{19}$ may reciprocally influence during the development, and jointly contribute to increase the risk of antisocial careers.

In terms of theoretical added value, the evaluation of the possible relationship between $\mathrm{CU}$ and moral disengagement could be useful to define a broader theoretical framework capturing the interplay between affective and cognitive processes to understand how the internal moral system works in youths at greater risk of following criminal pathways and developing antisocial disorders that would be then difficult to treat in adulthood. ${ }^{20}$ This could potentially result in practical implications for clinicians and psychologists operating in "at risk" social contexts. An integrated theoretical framework for the relationship between $\mathrm{CU}$ and moral disengagement could be also useful to design monitoring and intervention strategies for prevention and treatment of DBDs in adolescents at greater risk of emotional and moral detachment, and antisocial outcomes.

\section{CU and MD: The Affective and Cognitive Faces of (Un)Morality}

As pertain to $\mathrm{CU}$, authors suggested that they can designate a clinically important and etiologically distinct group of youths with conduct problems. CU traits involve lack of empathy and guilt, shallow and deficient emotions, and lack of care or concern about performance on tasks and others' feelings. ${ }^{21} \mathrm{CU}$ traits have been included in the DSM-5 as part of a new specifier to the diagnostic criteria of Conduct Disorder, named "with limited prosocial emotions" 22

Callous-unemotional features encompass peculiar cognitive, affective, personality, biological, genetic, and social characteristics $^{23}$. Globally, studies showed that youths with $\mathrm{CU}$ traits engage in more severe and persistent patterns of antisocial behavior like delinquency and substance use, ${ }^{24,25}$ and show lower levels of prosocial behavior, social competence skills, and emotional regulation. ${ }^{26}$ More specifically, adolescents with DBDs diagnosis and high CU are not empathic with their victims, use aggression proactively to achieve instrumental goals and social and material benefits without feeling any forms of remorse, and can be highly manipulative. ${ }^{10}$ Due to these characteristics, they represent the most at-risk subgroup of children and adolescents with $\mathrm{CD}$, highly disposed to becoming lifelong criminals. ${ }^{20}$

Some authors hypothesized that the moral affectivity impairment associated with $\mathrm{CU}$ might be due to temperamental dispositions (i.e., being fearless, insensitive to punishment, low responsiveness to cues of distress in others), which 
seems to interfere with the normative development of moral conscience. ${ }^{27}$ Moreover, studies suggested that youths with $\mathrm{CU}$ and behavioral problems exhibit an impairment in the ability to naturally allocate their attention to socially salient cues, which in turn prevent them from adequately processing and recognizing emotional stimuli. ${ }^{28}$ This appears extremely important because emotion recognition abilities are necessary to respond in an empathic way: if one cannot correctly identify distress caused to others, one is more likely to continue with harmful behaviors. Moreover, in a developmental study, CU has been posited to represent an impediment for the development of moral conscience since "callous youths are likely to exhibit permissive attitudes toward wrongdoing, especially when confronted with a potential justification for the act". ${ }^{15}$ Finally, studies showed widespread altered neural activation patterns that compromise moral evaluation. ${ }^{29} \mathrm{As}$ suggested by Blair and Cipollotti's model, ${ }^{30}$ a general emotional impairment may affect the development of moral thought, eventually leading to immoral and careless behavior.

With regard to cognitive processes, literature has extensively discussed the role of moral thinking in explanations of aggressive and deviant behaviors. In particular, authors have mainly focused their research on the link between moral thought and deviant behavior, suggesting that youths with low level of moral maturity are more at risk of engaging in antisocial behaviors. ${ }^{7}$ However, the presence of unmoral behavior of deviant adolescents does not necessarily imply a deficit in moral knowing. ${ }^{71}$ Indeed, despite callous adolescents can know the differences between what is right and what is wrong, ${ }^{8,31}$ this is not sufficient to motivate them towards good behavior or inhibit misbehavior. Concerning the inconsistency between moral thought and moral behavior, ${ }^{31,32}$ literature on aggression field ${ }^{33-35}$ has stressed the role of cognitive distortion in reframing the meaning of one's own and others' behavior providing an alternative "deviant" way to regulate (un)moral behavior. Cognitive distortion is an umbrella term referring to some processes that permit to interpret immoral behavior as appropriate and legitimized behavior with the aim of achieving one's own personal goals. The literature on cognitive distortion is extensive and different theoretical approaches and measures have been proposed, ${ }^{78,79}$ such as the theory of neutralization techniques, ${ }^{80}$ Gibbs's theory of selfserving cognitive, ${ }^{81}$ and the social learning theory. ${ }^{55,72}$ In the present study, we take into account the moral disengagement mechanisms, a conceptualization of self-serving cognitive distortions in a social cognitive framework. Specifically, the moral disengagement has been introduced by Bandura in the theory of Moral Agency. ${ }^{19,36}$ Bandura has highlighted that despite people are able to keep their conduct in line with their principles and systems of norms thanks to their self-regulatory capabilities, the moral self-regulatory moral system does not ensure behavioral consistency. Indeed, moral control could be selectively "deactivated" to protect one's own moral image. Moral disengagement mechanisms could come into play to resolve the dissonance between what individuals know to be the right thing to do and what they actually do. These self-serving processes operate by re-construing the meaning of harmful behaviors (behavioral locus), minimizing personal responsibility for antisocial acts (agency locus), disregarding the injurious consequences resulting from harmful conduct (outcome locus), and blaming and dehumanizing the victim (recipient locus). At the behavioral level, the aggressive and detrimental behavior can be made acceptable, less repugnant and even sanitized by means of moral justification, euphemistic language, and advantageous comparison. At the agency level, moral disengagement mechanisms operate to obscure or deny the personal responsibility of harm that one causes. This occurs through the displacement and diffusion of responsibility. At the outcome level, the mechanism of distortion of consequences permits to avoid self-deterring. The distortion of consequences is often highlighted in the literature on aggression, attesting that aggressive youths estimate more positive outcomes than negative ones as a result of their negative behavior. ${ }^{37,38}$ Moreover, the misrepresentation may involve active efforts to discredit evidence of the harm they cause. Finally, at recipient level, dehumanization divests people of human qualities - viewing persons as subhuman objects and attribution of blame permit to perceive aggressive actions as justifiable reactions resulting from the same target of their behavior.

These mechanisms could be learned and reinforced during the development through the observation of others' social interactions and through an individual's direct experience with others. Repeated stances of moral disengagement mechanism lead to its routinization and to the normalization of antisocial behavior. ${ }^{15,19}$ For some children, during development moral disengagement mechanisms could become crystallized into a "habitual" mindset that transforms reprehensible conduct into acceptable and appropriate means to pursue one's own goals. ${ }^{39}$

\section{Rationale \& Aims}

Consistently with the idea that $\mathrm{CU}$ and moral disengagement capture two kinds of processes - respectively, affective and cognitive - jointly operating in predicting aggressive and deviant behaviors, the general hypothesis of the present contribution is that in case of adolescents 
with disruptive behaviors, these two potentially pathogenic paths are strictly related and operate together. Indeed, it is possible to expect a coherent (un)moral functioning in adolescents regarding both emotional impairments and cognitive distortions. More specifically, as suggested by the literature on morality, ${ }^{9}$ individual differences, and aggression during the development ${ }^{15}$ we expect that moral affective processes can orient moral thinking. This is also in line with evidences from clinical and developmental studies that have examined separately $\mathrm{CU}$ and moral disengagement. On the one hand, $\mathrm{CU}$ is associated with the perception of aggression as an acceptable mean to interact with other, and with the minimizing of the harmful consequences. ${ }^{40}$ On the other hand, the activation of moral disengagement allows individuals to act despicable conduct avoiding remorse and guilt, ${ }^{19}$ and is promoted by low empathic concern for others. ${ }^{13,41}$ Moreover, a potential support for the interrelationship between $\mathrm{CU}$ and moral disengagement also derives from neuroscience studies. In particular, neuroimaging researches have attested that moral affective activation is strongly related to process concerning moral agency, ${ }^{42}$ and that in general, the relationship between cognitive and affective processes is essential to understand moral decision-making and the engagement in moral conducts. ${ }^{43}$

To explore the possible interplay between $\mathrm{CU}$ and moral disengagement the aim of the present review is to compile and discuss the existing literature on this topic integrating studies coming from different research areas interested to prevent and contrast disruptive behaviors and its antisocial outcomes. Indeed, a review of different theoretical approaches and methodologies can be helpful to put in evidence the nuances of possible interactions of $\mathrm{CU}$ and moral disengagement during adolescence, a sensible developmental phase for building of moral identity, ${ }^{32}$ escalation and chronicization of deviant behavior ${ }^{44}$ and related dysfunctional intra-individual processes. ${ }^{15,39}$

\section{Method}

This review is based on a systematic search of three relevant computer databases: PsycINFO, Pubmed, and Pubpsych. The search strategy combined terms to identify studies investigating $\mathrm{CU}$ traits and moral disengagement (MD) among youths (moral* OR cognitive distort* OR neutraliz* OR self serving OR empat*) AND (callous unemotional OR psychopathy) AND (child* OR adolescen* OR youth OR young). Wildcard operators $(*)$ were used to include all possible suffixes on a relevant search term (such as the terms "adolescence" and "adolescent" captured by the wildcard operator "adolescen*”).

The search was conducted on 7 January 2019 and 1005 records were identified (specifically, $\mathrm{N}=565$ on PsycINFO database; $\mathrm{N}=249$ on Pubmed and $\mathrm{N}=191$ on Pubpsych). From total records identified, $\mathrm{N}=292$ duplicate entries were removed. Then, titles and abstracts were screened to determine if the studies were eligible for inclusion.

The inclusion criteria were:

- The manuscript must have described original research (i.e., reviews and meta-analyses were not included);

- Studies must have considered both callous-unemotional traits and moral disengagement;

- Studies must have recruited samples composed by adolescent population (age range 11-19).

If questions about eligibility remained, then the entire article was reviewed to determine if inclusion criteria were met. Only published, peer-reviewed articles in English were selected and no limitations were put on publication dates.

Furthermore, references of review articles were evaluated to ensure no articles were missed. Three additional studies were included after this secondary review. So, the full texts of 28 potentially relevant studies were examined to assess whether they met the inclusion criteria of the review. After inspecting these 28 papers, 15 were removed (mostly because did not specifically evaluate moral disengagement in youths).

Figure 1 shows a flow diagram of the article review process.

Among the 13 studies resulting from the final selection, $\mathrm{N}=8$ have related the $\mathrm{CU}$ traits with the specific construct of moral disengagement, as conceptualized by Bandura, ${ }^{19,36,45}$ while $\mathrm{N}=5$ focused on moral thinking in relation to various aggressive/delinquent situations. Table 1 summarizes study characteristics. Thus, studies were reviewed in a narrative and qualitative synthesis, according to research aims.

All studies included in this review were original research published from 1990 to 2019. Specifically, research selected were $\mathrm{N}=4$ longitudinal studies ${ }^{13,15,46,48}$ and $\mathrm{N}=9$ cross-sectional studies. ${ }^{11,12,38,40,47,50-52,54}$

With regard to the Countries in which the studies examined were carried out, $\mathrm{N}=6$ studies were carried out in the 


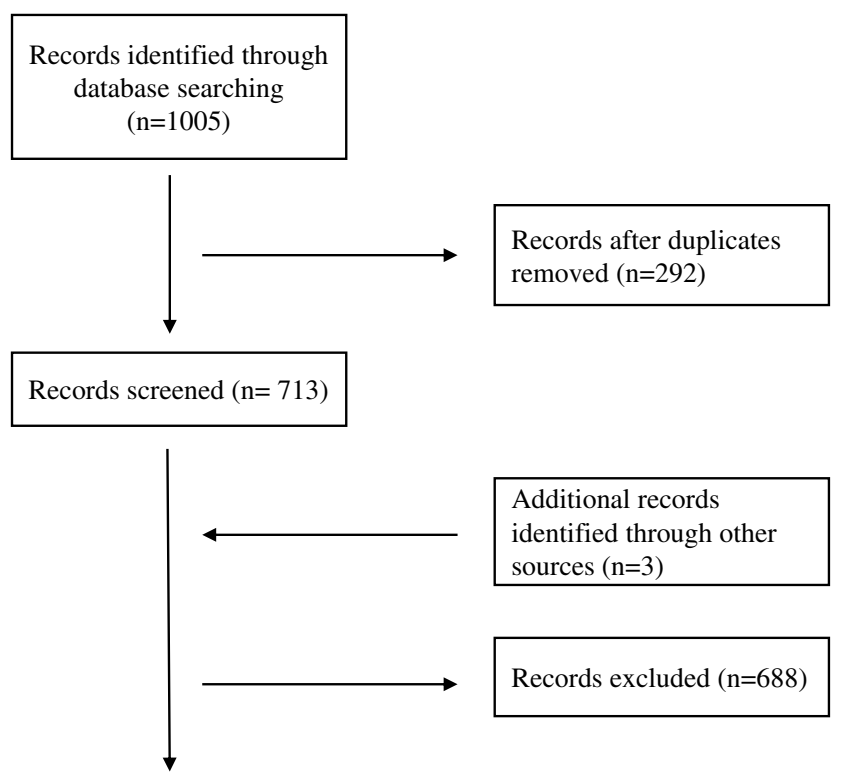

Full-text articles assessed for eligibility $(n=28)$

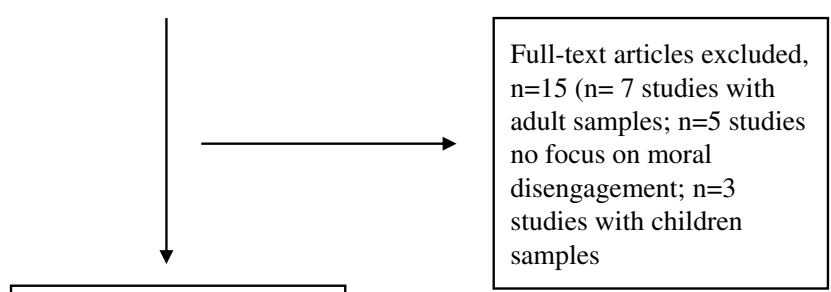

Studies included in qualitative synthesis $(\mathrm{n}=13)$

Figure I Flow diagram

USA, ${ }^{11,13,15,40,50,52} \mathrm{~N}=3$ in Italy, ${ }^{12,46,47}$ and the others in Netherland, ${ }^{48}$ Canada, ${ }^{51}$ Sweden, ${ }^{38}$ and France. ${ }^{54}$

\section{Studies' Characteristics}

On the basis of the journal in which the articles were published, it is clear that these concern different fields of research: clinical, developmental and criminological. Furthermore, across all 13 studies examined, $\mathrm{N}=4$ focused on community samples, ${ }^{12,38,48,54}$ and one study focused on high-risk sample; ${ }^{13}$ furthermore, $\mathrm{N}=6$ studies considered adjudicated juvenile delinquent ${ }^{11,15,40,50-52}$ and $\mathrm{N}=2$ considered samples of adolescents diagnosed with disruptive behavior disorder. ${ }^{46,47}$ Interestingly, studies on sample of adolescents diagnosed with DBD were performed only in Italy, while studies on juvenile offenders or adjudicated delinquent were carried out mostly in the USA. The sample size was bigger in studies with adjudicated juvenile delinquent adolescents.
As regards measures to assess moral disengagement, $\mathrm{N}=$ 8 studies used MDS $^{11-13,15,46-48,50}$ and all these studies have reported internal consistent values of MDS, with Cronbach's alpha ranged from 0.77 to 0.91 . Other studies used other tools (i.e., vignettes, interviews, and self-report questionnaires) to assess moral thinking in relation to various aggressive/delinquent situations. Specifically, Chandler and Moran ${ }^{51}$ used Moral Judgment Interview on three dilemmas; $\mathrm{N}=3$ studies used vignettes: Lorber et $\mathrm{al}^{52}$ and Pardini et $\mathrm{al}^{40}$ used OEQ e OVQ, while Thornberg and Jungert ${ }^{38}$ used vignettes relating to bullying situations. Finally, van Leeuwen et al $^{54}$ used a self-report questionnaire for self-serving cognitions, The How I Think Questionnaire. ${ }^{65}$

As regards the $\mathrm{CU}$ traits, one study used report form questionnaire filled out by parents ${ }^{46}$ (APSD-PR) and another study used cross informant measure ${ }^{13}$ (CADS, filled out by parents and youths). However, most studies used self-report questionnaires: YPI, ${ }^{11,15,54}$ YPI-SCV, ${ }^{12}$ ICU-Y, ${ }^{38,40,47,52}$ Dirty Dozen, ${ }^{48}$ PCL: $\mathrm{YV}^{50}$ and the 17item version of PCL. ${ }^{51}$ Finally, $\mathrm{N}=2$ studies used in addiction the self-report questionnaire APSD. ${ }^{40,52}$

Some studies did not report Cronbach's alpha for measures to assess CU traits, ${ }^{40,51}$ while Cronbach's alpha reported by the other studies ranged from 0.71 to 0.90 . Studies on community samples have assessed aggressive or delinquent behaviors with different selfreport measures: Aggressive behavior 24 items selfreport scale, ${ }^{12,66}$ Antisocial Behavior Questionnaire, ${ }^{48,67}$ Direct and indirect aggression scale, ${ }^{48,68}$ Self-Report of Delinquency Questionnaire, ${ }^{13,69}$ The Revised Olweus Bully/Victim Questionnaire, ${ }^{38}$ and the Questionnaire de Délinquance Autorévélée. ${ }^{54,70}$ Cronbach's alpha for these measures ranged from 0.81 to 0.92 .

\section{Results}

On the basis of the research question, studies were grouped based on the patterns of relationships that emerged among the variables investigated (CU, moral disengagement, and externalizing behaviors). Starting from Chandler and Moran's study, ${ }^{51}$ several years later, Pardini et $\mathrm{al}^{40}$ and Lorber et $\mathrm{al}^{52}$ (who replicated Pardini's study) studied the relationship between $\mathrm{CU}$ and the outcome expectations in aggressive situations, and found mixed results. Specifically, while Pardini et $\mathrm{al}^{40}$ found that $\mathrm{CU}$ traits predicted the outcome expectancy variables, Lorber et $\mathrm{al}^{52}$ did not find this association.

Therefore, research has become increasingly interested in the relationships between these variables. Gini et $\mathrm{al}^{12}$ 
Table I Characteristics of Included Studies

\begin{tabular}{|c|c|c|c|c|c|c|c|c|}
\hline Study & Design & Country & $\begin{array}{l}\text { Sample } \\
\text { Size }\end{array}$ & $\begin{array}{l}\text { Type of } \\
\text { Sample }\end{array}$ & $\begin{array}{l}\% \\
\text { Females }\end{array}$ & $\begin{array}{l}\text { Age Range } \\
\text { (Years) }\end{array}$ & $\begin{array}{l}\text { Measure of Moral } \\
\text { Disengagement }\end{array}$ & $\begin{array}{l}\text { Measure of } \mathrm{CU} \\
\text { Traits }\end{array}$ \\
\hline \multicolumn{9}{|l|}{ Moral disengagement } \\
\hline DeLisi et al" & C & USA & $N=252$ & Clinic-referred & $39.68 \%$ & $14-18$ & $\begin{array}{l}\text { 15-item version of the } \\
\text { MDS }(Y)\end{array}$ & YPI (Y) \\
\hline Gini et al ${ }^{12}$ & C & Italy & $N=243$ & Representative & $41.56 \%$ & $11-15$ & $\begin{array}{l}\text { I4-item version of the } \\
\text { MDS }(Y)\end{array}$ & YPI-SCV (Y) \\
\hline Hyde et al ${ }^{13}$ & L & USA & $N=187$ & High risk & $0 \%$ & $\begin{array}{l}\text { From } 1.5 \text { years } \\
\text { to } 15-17\end{array}$ & MDS (Y) & CADS $(P ; Y)$ \\
\hline Muratori et $\mathrm{al}^{46}$ & $\mathrm{~L}$ & Italy & 55 & Clinic-referred & $9.09 \%$ & $13-16$ & MDS (Y) & APSD-PR (P) \\
\hline Paciello et al ${ }^{47}$ & C & Italy & $N=90$ & Clinic-referred & $14.4 \%$ & $11-18$ & MDS (Y) & ICU-Y $(Y)$ \\
\hline Shulman et al ${ }^{15}$ & $\mathrm{~L}$ & USA & $N=1169$ & Clinic-referred & $0 \%$ & $14-17$ & MDS (Y) & YPI (Y) \\
\hline Sijtsema et al ${ }^{48}$ & L & Nether & $\begin{array}{l}N=502 \\
-206\end{array}$ & Representative & $49 \%$ & $\begin{array}{l}\text { Mean age at first } \\
\text { wave }=13.57\end{array}$ & MDS (Y) & Dirty Dozen ${ }^{49}(Y)$ \\
\hline $\begin{array}{l}\text { Walters and } \\
\text { DeLisi }{ }^{50}\end{array}$ & C & USA & $N=1354$ & Clinic-referred & $13,59 \%$ & $14-17$ & MDS (Y) & PCL: YV (Y) \\
\hline \multicolumn{9}{|l|}{ Moral thinking } \\
\hline $\begin{array}{l}\text { Chandler and } \\
\text { Moran }^{51}\end{array}$ & C & Canada & $N=80$ & Clinic-referred & $0 \%$ & $14-17$ & $\begin{array}{l}\text { Three dilemmas from } \\
\text { Kohlberg's standard Moral } \\
\text { Judgment Interview (MJI) (I) }\end{array}$ & $\begin{array}{l}\text { I7-item version } \\
\text { of } P C L(Y)\end{array}$ \\
\hline Lorber et $\mathrm{al}^{52}$ & C & USA & $N=76$ & Representative & $25 \%$ & $10-19$ & $\begin{array}{l}\text { OEQ (V) } \\
\text { OVQ (V) }\end{array}$ & $\begin{array}{l}\text { ICU-Y (Y) } \\
\text { APSD (Y) }\end{array}$ \\
\hline Pardini et $\mathrm{al}^{40}$ & C & USA & $N=169$ & Clinic-referred & $42.6 \%$ & $\begin{array}{l}\text { Mean age } 15.8 \mid \\
(s d=\mid .26)\end{array}$ & $\begin{array}{l}\text { OEQ (V) } \\
\text { OVQ (V) }\end{array}$ & $\begin{array}{l}\text { APSD (Y) } \\
\text { IRI (Y) }\end{array}$ \\
\hline $\begin{array}{l}\text { Thornberg and } \\
\text { Jungert }^{38}\end{array}$ & C & Sweden & $N=38 I$ & Representative & $48.03 \%$ & $10-13.5$ & $\begin{array}{l}\text { Vignettes for Moral } \\
\text { reasoning in Bullying }{ }^{53}(\mathrm{~V})\end{array}$ & ICU-Y $(Y)$ \\
\hline Van Leeuwen et $\mathrm{al}^{54}$ & C & France & $N=972$ & Representative & $49 \%$ & $|4-2|$ & HIT-Q (Y) & YPI (Y) \\
\hline
\end{tabular}

Notes: Design: L $=$ Longitudinal study; $C=$ Cross-sectional study; $\mathrm{P}=$ Prospective. Country: Nether $=$ Netherlands. Measures: $\mathrm{MDS}=$ Moral Disengagement Scale ${ }^{55} \mathrm{YPI}=$ Youth Psychopathic traits Inventory; ${ }^{56}$ YPI-SCV $=$ Youth Psychopathic Traits Inventory-Short Child Version; ${ }^{57}$ CADS $=$ Child and Adolescent disposition Scale; ${ }^{58}$ APSD-PR $=$ Antisocial Process Screening device-parent report; ${ }^{59} \mathrm{ICU}-\mathrm{Y}=$ Inventory of Callous-Unemotional Traits - Youth version; ${ }^{60} \mathrm{PCL}: \mathrm{YV}=$ Psychopathy Checklist: Youth Version; ${ }^{61} \mathrm{OEQ}=$ Outcome Expectancy Questionnaire $\left(\mathrm{OEQ}^{62}\right)$; OVQ = Outcome Values Questionnaire; ${ }^{63} \mathrm{IRI}=$ The Interpersonal Reactivity Index, ${ }^{64} \mathrm{HIT}-\mathrm{Q}\left(\right.$ The How $^{6}$ I Think Questionnair $\left.{ }^{65}\right)$. Informant: $(Y)=$ youth; $(P)=$ parent; $(I)=$ interview; $(V)=$ vignette.

assumed that the relationships between the variables followed the model shown in Figure 2. On the other hand, the study found that moral disengagement moderated the relationship between impulsive-irresponsible traits and aggression and between grandiose-manipulative traits and aggressive behavior, but not between $\mathrm{CU}$ traits and aggressive behavior.

Thus, authors did not find a moderation effect of the moral disengagement in the CU-Externalizing behavior relationship. On the other hand, the retrospective study of DeLisi et $\mathrm{al}^{11}$ aimed to verify the moderation role of $\mathrm{CU}$ traits; the authors found that moral disengagement mediated the relationship between $\mathrm{CU}$ and earlier criminal onset, only when youths reported low psychopathy. It should be noted that most of the studies proposed and verified the model shown in Figure 3, in which moral disengagement mediates the relationship between $\mathrm{CU}$ and Externalizing behaviors.

Specifically, Hyde et $\mathrm{al}^{13}$ longitudinally studied the precursors of moral disengagement in adolescence, finding the mediator role of moral disengagement. In fact, this study found that empathy assessed at 12 years of age was the most robust negative predictor of moral disengagement in later adolescence. This study has verified a path in which high levels of rejecting parenting may lead to lower levels of empathy and contribute with 


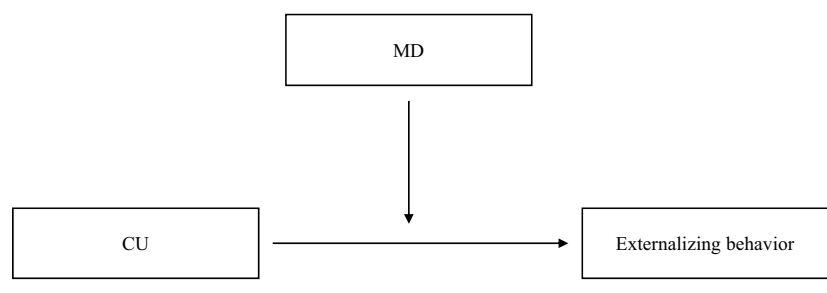

Figure 2 Moral disengagement moderates the relationship between $\mathrm{CU}$ and externalizing behavior.

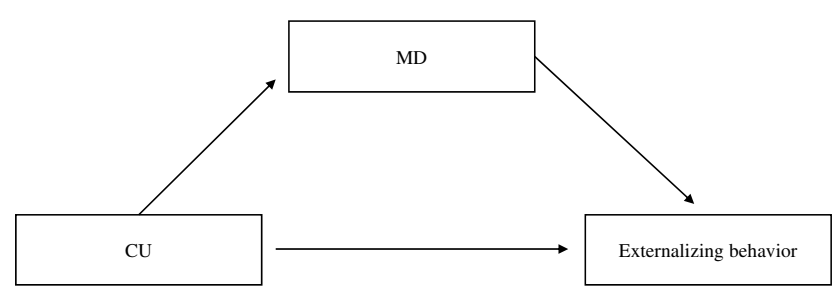

Figure 3 Moral disengagement mediates the relationship between $\mathrm{CU}$ traits and externalizing behaviors.

neighborhood impoverishment to high moral disengagement linking to later antisocial behavior.

Furthermore, results of Walters and DeLisi's study ${ }^{50}$ found the mediator role of moral disengagement in the relationship between core personality features of psychopathy and violence and in the relationship between behavioral deviance and violence.

Also Thornberg and Jungert ${ }^{38}$ verified the model shown in Figure 3. The results of this study suggested that $\mathrm{CU}$ traits were indirectly associated with bullying through the reduced use of harm-effect moral reasoning. Moreover, in a longitudinal study with juvenile offenders, Shulman et $\mathrm{al}^{15}$ found that moral disengagement and offending behavior decreased over time and their longitudinal relationship persisted even after accounting for the significant effects of $\mathrm{CU}$ on both moral disengagement and self-report offending. Furthermore, the authors found that $\mathrm{CU}$ traits were strongly correlated with moral disengagement and moderately correlated with self-reported offending, suggesting that the contribution of $\mathrm{CU}$ traits to antisocial behavior is distinct from that of moral disengagement. All these studies verified the model in Figure 3. However, the interesting results of the van Leeuwen et $\mathrm{al}^{54}$ study should be highlighted. In fact, the authors found two possible alternative models. If on the one hand, one model showed as self-serving cognitions mediated the relationships between CU traits and antisocial behaviors (as illustrated in Figure 3), on the other hand, authors also found that $\mathrm{CU}$ traits mediated the relationship between self-

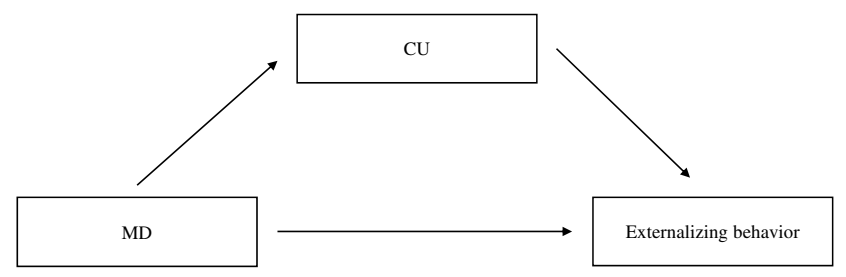

Figure $4 \mathrm{CU}$ traits mediated the relationship between self-serving cognitions and antisocial behaviors.

serving cognitions and antisocial behaviors (see Figure 4). This model was stronger in boys.

Moreover, Sijtsema et $\mathrm{al}^{48}$ aimed to verify longitudinal relationship between $\mathrm{MD}$, dark personality characteristics (Machiavellianism, narcissism, and psychopathy) and antisocial behaviors in adolescents. These authors found no support for the hypothesis of the mediator role of moral disengagement. Instead, authors found the longitudinal influences of antisocial behavior on moral disengagement and on dark personality, but only in boys, underlining the weight of past behaviors (Figure 5).

Thus, it is possible to see that the studies underlined a complex relationship between these constructs. As a matter of fact, the study of Muratori et $\mathrm{al}^{46}$ found a complex and reciprocal interplay between $\mathrm{CU}$ and moral disengagement (see Figure 6).

Specifically, authors found that higher levels of moral disengagement when youth were 14 years old predicted higher levels of $\mathrm{CU}$ traits one year later; nonetheless, the authors also found that $\mathrm{CU}$ traits at 14 years old predicted higher levels of moral disengagement one year later. Interestingly, rule-breaking behavioral problems were significantly predicted from moral disengagement and not from CU.

Also, investigating these complex relationships between moral disengagement and $\mathrm{CU}$, interesting results were found from Paciello et $\mathrm{al}^{47}$ which aimed to identify $\mathrm{CU}$ and moral disengagement configurations in adolescents with DBD diagnosis. Results found three different

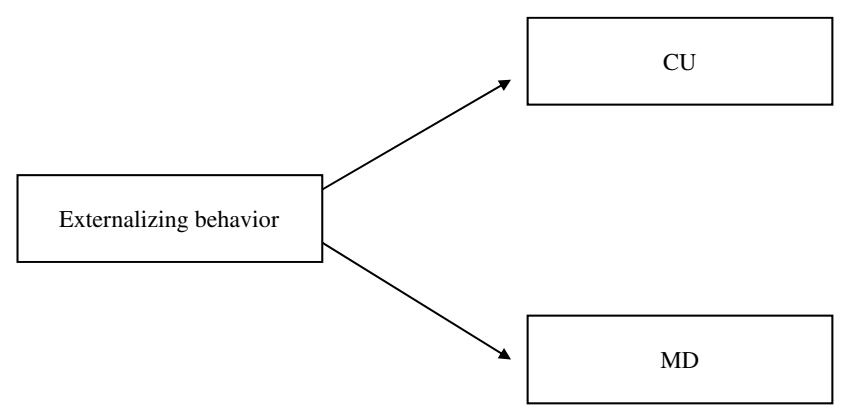

Figure 5 Externalizing behaviors predict moral disengagement and CU. 


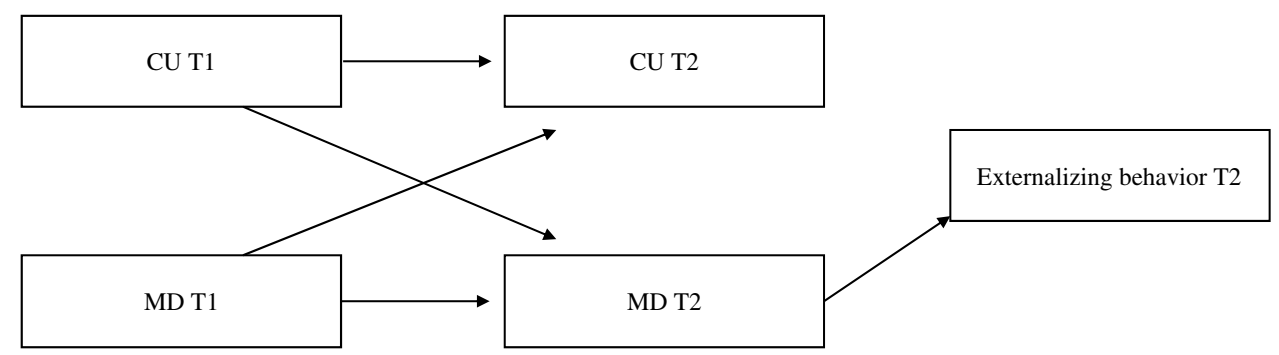

Figure 6 Model found in the study of Muratori et al. ${ }^{46}$

clusters of adolescents on the base of moral disengagement and CU traits. Specifically, this study found a cluster characterized by high levels of both $\mathrm{CU}$ and moral disengagement, a cluster characterized by low scores of the same another cluster composed by adolescents with high levels of $\mathrm{CU}$ and average-low levels of moral disengagement. Investigating the relationship between clusters identified and behavioral profiles, these authors found that the interplay between higher moral disengagement and CU was associated with an increased severity of externalizing behaviors.

\section{Discussion}

The first result of the present review concerns the paucity of studies that had jointly investigated both CU and moral disengagement. Moreover, the few studies on this topic come from three research fields (clinical, developmental, and criminological), that draw their studies rooting on different theoretical and methodological approaches. Indeed, the current review suggests some possible conclusions by integrating these different approaches by focusing on the diverse possible behavioral manifestations associated with DBD, as, for example, bullying in the case of development field, aggression, and externalizing behaviors in the case of clinical psychology, and offences in the case of criminological research area.

Overall, one main model posited that moral disengagement mechanisms mediate the relationship between psychopathic traits and aggressive and deviant behavior. ${ }^{50}$ However, also other alternative models were posited and tested. One proposes that these kind of self-serving cognitive distortion mediates the relationship between aggressive and deviant behavior and psychopathic tendency. ${ }^{48}$ A second one suggests that moral disengagement could influence $\mathrm{CU},{ }^{54}$ other models have posited a possible moderation of $\mathrm{CU}^{11}$ or moral disengagement ${ }^{12}$ and finally some authors have suggested that during the development these two individual dimensions reciprocally influence ${ }^{46}$ and are strictly interrelated in the more serious cases. ${ }^{47}$
With regard to the main model, the hypothesis is in line with clinical $^{71}$ and more general moral literature ${ }^{9}$ attesting that affective processes can affect moral cognitive ones. In the specific case of CU and moral disengagement, the emotional impairment of DBDs adolescents could lead to cognitive process supporting unmorally behaviors. The effect of $\mathrm{CU}$ on moral disengagement that in turn affect behavior has been supported in Shulman et al's longitudinal study ${ }^{15}$ and Walters and DeLisi's work ${ }^{50}$ attesting that moral disengagement could be a result of emotional dysfunction. This path suggests that a way of contrasting the development of moral disengagement mindset could be the improvement of emphatic and emotional skills. The difficulty of DBD's cluster with $\mathrm{CU}$ to feel the others needs and to recognize their rights can facilitate the adoption of self-serving processes that normalize and legitimate damaging behavior during social interactions. Parallel, the frequent recourse to harmful and aggressive behavior associated with emotional impairment of these adolescents can represent an adding risk factor in the routinization of self-serving justification. Indeed, in line with Bandura's theory, ${ }^{19}$ some studies have underlined that not only affective dimension but also past behavior may influence the adoption of moral disengagement mechanisms (especially in the case of boys ${ }^{48}$ ).

With regard to the influence of moral disengagement on $\mathrm{CU}$, longitudinal studies attested that the recourse to moral disengagement mechanisms is related to a decrease in moral emotions, such as guilt, ${ }^{39}$ which may result in an increase of psychopathic traits. ${ }^{46,48}$ In fact, moral disengagement may lead to a sort of "moral desensitization", with the subject becoming gradually more tolerant towards the discomfort "until, eventually, acts originally regarded as abhorrent can be performed without much distress" 72 This possible path suggested that intervention on specific social informationprocessing patterns could influence the development of CU. For example, in line with clinical literature ${ }^{40}$ (with the only except for one $\mathrm{study}^{52}$ ), adolescents with CU can benefit from intervention on cognitive processes related to the 
outcome distortion since they are hyper-focused on reward and less focused to cues of punishment, ${ }^{73}$ more concerned about dominating others, ${ }^{37}$ and careless to harm-effect of their behavior. ${ }^{38}$

Some moderating hypotheses in literature are also noteworthy. With regards to the role of moral disengagement as a moderator, there is only one cross-sectional study on a community sample ${ }^{12}$ that shows a nonsignificant interaction between these variables when examining proactive and reactive aggression. With regard to moderating role of $\mathrm{CU}$, the conclusions are contrasting. On one hand, echoing Stams' meta-analysis, ${ }^{7}$ criminological literature ${ }^{11}$ has suggested that psychopathic traits could moderate the relationship between moral disengagement and antisocial behavior (i.e., delinquency). In other terms male adolescents with $\mathrm{CU}$ traits could not necessitate disengaging to reduce a possible sense of guilt or remorse, they just do. ${ }^{11}$ However, in the developmental field when serious offenders with and without $\mathrm{CU}$ were compared ${ }^{15}$ the effect on moral disengagement on offences is significant in both cases. In addition, in the clinical studies, ${ }^{46,47}$ the cluster of adolescents with high CU may or may not show high level of moral disengagement, but only in the case of high moral disengagement, they show the most compromised profile. More specifically, DBD adolescents with higher levels of both $\mathrm{CU}$ and moral disengagement presented present higher levels of both aggressive and rule braking behaviors indicating a severely impaired profile.

Overall, most of scholars seem to conclude that different models can be plausible, suggesting that it is likely that during the adolescence the influence of moral disengagement and $\mathrm{CU}$ is reciprocal and longitudinal. ${ }^{46} \mathrm{CU}$ and moral disengagement can move together in organizing and becoming chronic of antisocial affective-cognitive system, and in particular moral disengagement may give a free way to engage in disruptive behavior in adolescents with DBDs. The interplay between moral disengagement and CU could be crucial especially in the case of the cluster of adolescents with disruptive behavior, that are more demanding during the intervention processes and more compromised in prognostic terms. Especially for these adolescents it could be important to take into account also moral disengagement planning new intervention programs to reduce the levels of $\mathrm{CU}$ traits. ${ }^{82}$ These programs might target moral disengagement mechanisms that may promote high levels of CU traits in children and adolescents. However, no previous treatment studies have explicitly investigated moral disengagement as a possible intervention's target, despite the literature have showed that moral disengagement may lead to escalation of aggressive behaviors during childhood and adolescence in criminological, developmental and clinical fields. Thus, possible intervention implications of the present review may be (1) using specific tools to evaluate the levels of both $\mathrm{CU}$ and moral disengagement in screening and/or assessment of children and adolescents (2) tailoring more specific interventions for the different needs of youths, according to moral disengagement and $\mathrm{CU}$ levels. It is plausible that such interventions should include not only strategies to improve empathy capacity (the core deficit of CU traits) but also strategies to improve the individual's moral self-regulative functioning. For example, it could be useful to focus also on the motivational factor of behavior. To this end, our previous study showed that selftranscendence values may inhibit moral disengagement and promote prosocial behaviors ${ }^{83}$ so this would provide one strategy for the developers of new prevention intervention programs.

\section{Conclusion and Future Research}

It is important to underline that the studies presented here have different methodological differences. In particular, some studies employed longitudinal designs while others used a crosssectional approach. Longitudinal studies are the studies better able to shed light on the investigated interplay between callousunemotional traits, moral disengagement, and disruptive behavior, specifically in developmental age. Nevertheless, it is interesting to note that longitudinal studies also show mixed results. While Hyde et $\mathrm{al}^{13}$ found the mediator role of moral disengagement, Shulman et $\mathrm{al}^{15}$ found that the contribution of $\mathrm{CU}$ traits to antisocial behavior is distinct from that of moral disengagement. On the other hand, Sijtsema et al ${ }^{48}$ found the longitudinal influences of antisocial behavior on moral disengagement and CU, but only in boys. Finally, Muratori et $\mathrm{al}^{46}$ found a complex and reciprocal interplay between $\mathrm{CU}$ and moral disengagement. As you can see, several longitudinal studies also show that the relationship between these variables is complex in this specific age group. Moreover, based on different lens and approach (clinical, developmental, and criminological), the behavioral outcomes changed. Thus, it is possible that some inconsistencies among research results are also due to different examined behaviors that could be a different phenotypic expression of the same problem during the development.

Notwithstanding these methodological issue, the present review suggests that the stability of these maladaptive processes is related to complex interactions between the 
social contextual factor that support biological characteristics that do not necessarily imply an implacable condemnation. Indeed, for both moral disengagement and $\mathrm{CU}$, trajectory models were estimated attesting a great variability during development. ${ }^{39,74}$ Unfortunately, to our best knowledge, no study has tested combined trajectories to verify whether the chronicizing of both processes is predicted by their reciprocal interaction.

In sum, the present review suggests that it is important to take into account both $\mathrm{CU}$ and moral disengagement especially in the case of more compromised cluster of disruptive behavior. It is probable that for these adolescents a vicious circle in which affective and cognitive processes maintain a moral and interpersonal disinvestment, exacerbates their problems during the development. ${ }^{74-76}$ For these reasons, both these constructs can be important targets of intervention, but more effort should be put to understand how they operate together to prevent antisocial careers.

\section{Disclosure}

The authors report no conflicts of interest in this work.

\section{References}

1. Burt SA, Hyde LW, Frick PJ, Jaffee SR, Shaw DS, Tremblay R. Commentary: childhood conduct problems are a public health crisis and require resources: a commentary on Rivenbark et al. $J$ Child Psychol Psychiatry. 2018;59:711-713. doi:10.1111/jcpp.12930

2. Steiner H, Remsing L. Practice parameter for the assessment and treatment of children and adolescents with oppositional defiant disorder. J Am Acad Child Adolesc Psychiatry. 2007;46(1):126-141. doi:10.1097/01.chi.0000246060.62706.af

3. Murrihy RC, Kidman AD, Ollendick TH, eds. Clinical Handbook of Assessing and Treating Conduct Problems in Youth. New York: Springer Science \& Business Media; 2010.

4. Fergusson DM, John Horwood L, Ridder EM. Show me the child at seven: the consequences of conduct problems in childhood for psychosocial functioning in adulthood. $J$ Child Psychol Psychiatry. 2005;46(8):837-849. doi:10.1111/jcpp.2005.46.issue-8

5. American Psychiatric Association, Diagnostic and Statistical Manual of Mental Disorders. 4th ed. Text rev. Washington, DC: Author; 2000: 223-234.

6. Frick PJ, Blair RJ, Castellanos FX. Callous-unemotional traits and developmental pathways to the disruptive behavior disorders. In: Tolan PH, Leventhal BL, editors. Disruptive Behavior Disorders. New York: Springer; 2013:69-102.

7. Stams GJ, Brugman D, Dekovic M, van Rosmalen L, van der Laan P, Gibbs JC. The moral judgment of juvenile delinquents: a meta-analysis. J Abnorm Child Psychol. 2006;34:697-713. doi:10.10 07/s10802-006-9056-5

8. Cima M, Korebrits A, Stams GJ, Bleumer P. Moral cognition, emotion, and behavior in male youth with varying levels of psychopathic traits. International Journal of Law and Psychiatry. 2017;54:155-162. doi:10.1016/j.ijlp.2017.06.011
9. Haidt J. The emotional dog and its rational tail: a social intuitionist approach to moral judgment. Psychol Rev. 2001;108(4):814-834. doi:10.1037/0033-295X.108.4.814

10. Frick PJ, Marsee MA, Patrick C. Psychopathy and developmental pathways to antisocial behavior in youth. In: Patrick CJ, editor. Handbook of Psychopathy. London: The Guilford Press; 2006:353-374.

11. DeLisi M, Peters DJ, Dansby T, Vaughn MG, Shook JJ, Hochstetler A. Dynamics of psychopathy and moral disengagement in the etiology of crime. Youth Violence Juv Justice. 2014;12 (4):295-314. doi:10.1177/1541204013506919

12. Gini G, Pozzoli T, Bussey K. Moral disengagement moderates the link between psychopathic traits and aggressive behavior among early adolescents. Merrill Palmer $Q$ (Wayne State Univ Press). 2015;61(1):51-67. doi:10.13110/merrpalmquar1982.61.1.0051

13. Hyde LW, Shaw DS, Moilanen KL. Developmental precursors of moral disengagement and the role of moral disengagement in the development of antisocial behavior. J Abnorm Child Psychol. 2010;38:197-209. doi:10.1007/s10802-009-9358-5

14. Kokkinos CM, Voulgaridou I, Markos A. Personality and relational aggression: moral disengagement and friendship quality as mediators. Pers Individ Dif. 2016;95:74-79. doi:10.1016/j.paid.2016.02.028

15. Shulman EP, Cauffman E, Piquero AR, Fagan J. Moral disengagement among serious juvenile offenders: a longitudinal study of the relations between morally disengaged attitudes and offending. Dev Psychol. 2011;47(6):1619-1632. doi:10.1037/a0025404

16. Risser $\mathrm{S}$, Eckert K. Investigating the relationships between antisocial behaviors, psychopathic traits, and moral disengagement. Int J Law Psychiatry. 2016;45:70-74. doi:10.1016/j.ijlp.2016.02.012

17. Larsson H, Andershed H, Lichtenstein P. A genetic factor explains most of the variation in the psychopathic personality. $J$ Abnorm Psychol. 2006;115(2):221-230. doi:10.1037/0021-843X.115.2.221

18. Taylor J, Loney BR, Bobadilla L, Iacono WG, McGue M. Genetic and environmental influences on psychopathy trait dimensions in a community sample of male twins. J Abnorm Psychol. 2003;31 (6):633-645. doi:10.1023/A:1026262207449

19. Bandura A, Jourden FJ. Self-regulatory mechanisms governing the impact of social comparison on complex decision making. J Pers Soc Psychol. 1991;60(6):941-951. doi:10.1037/0022-3514.60.6.941

20. Gibbon S, Duggan C, Stoffers J, et al. Psychological interventions for antisocial personality disorder. Cochrane Database Syst Rev. 2010;16 (6):CD007668.

21. Frick PJ, Stickle TR, Dandreaux DM, Farrell JM, Kimonis ER. Callous-unemotional traits in predicting the severity and stability of conduct problems and delinquency. J Abnorm Child Psychol. 2005;33:471-487. doi:10.1007/s10648-005-5728-9

22. American Psychiatric Association. Diagnostic and Statistical Manual of Mental Disorders: DSM-5. American Psychiatric Publishing; 2013.

23. Campbell J, Schermer JA, Villani VC, Nguyen B, Vickers L, Vernon PA. A behavioral genetic study of the Dark Triad of personality and moral development. Twin Res Hum Genet. 2009;12 (2):132-136. doi:10.1375/twin.12.2.132

24. López-Romero L, Romero E, Luengo MA. Disentangling the role of psychopathic traits and externalizing behaviour in predicting conduct problems from childhood to adolescence. J Youth Adolesc. 2012;41 (11):1397-1408. doi:10.1007/s10964-012-9800-9

25. McMahon RJ, Witkiewitz K, Kotler JS. Predictive validity of callous-unemotional traits measured in early adolescence with respect to multiple antisocial outcomes. J Abnorm Psychol. 2010;119(4):75 2-763. doi:10.1037/a0020796

26. Masi G, Muratori P, Manfredi A, Pisano S, Milone A. Child behaviour checklist emotional dysregulation profiles in youth with disruptive behaviour disorders: clinical correlates and treatment implications. Psychiatry Res. 2015;225(1-2):191-196. doi:10.1016/j.psychres.2014.11.019 
27. Frick PJ, Viding E. Antisocial behavior from a developmental psychopathology perspective. Dev Psychopathol. 2009;21(4):1111-1131. doi:10.1017/S0954579409990071

28. Billeci L, Muratori P, Calderoni S, et al. Emotional processing deficits in Italian children with disruptive behavior disorder: the role of callous unemotional traits. Behav Res Ther. 2019;113:32-38. doi:10.1016/j.brat.2018.12.011

29. Zijlmans J, Marhe R, Popma A. Error-related brain activity and long-term cannabis use in multiproblem young adults: preliminary EEG results. Eur Neuropsychopharmacol. 2016;2(26):S684. doi:10.1016/S0924-977X(16)31807-7

30. Blair RJ, Cipolotti L. Impaired social response reversal: a case of acquired sociopathy. Brain. 2000;123(6):1122-1141. doi:10.1093/ brain/123.6.1122

31. Aharoni E, Sinnott-Armstrong W, Kiehl KA. Can psychopathic offenders discern moral wrongs? A new look at the moral/conventional distinction. J Abnorm Psychol. 2012;121(2):484 497. doi:10.1037/a0024796

32. Blasi A. Bridging moral cognition and moral action: a critical review of the literature. Psychol Bull. 1980;88(1):1-45. doi:10.1037/0033-2909.88.1.1

33. Anderson CA, Bushman BJ. Effects of violent video games on aggressive behavior, aggressive cognition, aggressive affect, physiological arousal, and prosocial behavior: a meta-analytic review of the scientific literature. Psychol Sci. 2001;12(5):353-359. doi:10.1111/1467-9280.00366

34. Brugman D, Bink MD. Effects of the EQUIP peer intervention program on self-serving cognitive distortions and recidivism among delinquent male adolescents. Psychol Crime Law. 2011;17(4):34 5-358. doi:10.1080/10683160903257934

35. Crick NR, Dodge KA. A review and reformulation of social information-processing mechanisms in children's social adjustment. Psychol Bull. 1994;115(1):74-101. doi:10.1037/0033-2909.115.1.74

36. Bandura A. Selective activation and disengagement of moral control. J Soc Issues. 1990;46(1):27-46. doi:10.1111/josi.1990.46.issue-1

37. Pardini DA, Byrd AL. Perceptions of aggressive conflicts and others' distress in children with callous-unemotional traits: 'I'll show you who's boss, even if you suffer and I get in trouble'. J Child Psychol Psychiatry. 2012;53(3):283-291. doi:10.1111/j.1469-7610.2011.02487.x

38. Thornberg R, Jungert T. Callous-unemotional traits, harm-effect moral reasoning, and bullying among Swedish children. Child Youth Care Forum. 2017;46(4):559-575. doi:10.1007/s10566-017-9395-0

39. Paciello M, Fida R, Tramontano C, Lupinetti C, Caprara GV. Stability and change of moral disengagement and its impact on aggression and violence in late adolescence. Child Dev. 2008;79:1288-1309. doi:10.1111/j.1467-8624.2008.01189.x

40. Pardini DA, Lochman JE, Frick PJ. Callous/unemotional traits and social-cognitive processes in adjudicated youths. J Am Acad Child Adolesc Psychiatry. 2003;42:364-371. doi:10.1097/00004583-20030 3000-00018

41. Paciello M, Fida R, Cerniglia L, Tramontano C, Cole E. High cost helping scenario: the role of empathy, prosocial reasoning and moral disengagement on helping behavior. Pers Individ Dif. 2013;55 (1):3-7. doi:10.1016/j.paid.2012.11.004

42. Moll J, Oliveira-Souza RD, Garrido GJ, et al. The self as a moral agent: linking the neural bases of social agency and moral sensitivity. Soc Neurosci. 2007;2(3-4):336-352. doi:10.1080/17470910701392024

43. Greene JD, Sommerville RB, Nystrom LE, Darley JM, Cohen JD. An fMRI investigation of emotional engagement in moral judgment. Science. 2001;293(5537):2105-2108. doi:10.1126/science.1062872

44. Moffitt TE. Adolescence-limited and life-course-persistent antisocial behavior: a developmental taxonomy. Psychol Rev. 1993;100: 674-701. doi:10.1037/0033-295X.100.4.674

45. Bandura A. Moral Disengagement: How People Do Harm and Live with Themselves. New York: Worth Publishers; 2016.

46. Muratori P, Paciello M, Buonanno C, et al. Moral disengagement and callous-unemotional traits: a longitudinal study of Italian adolescents with a disruptive behaviour disorder. Crim Behav Ment Health. 2017;27(5):514-524. doi:10.1002/cbm.v27.5
47. Paciello M, Masi G, Clemente MG, Milone A, Muratori P. Moral disengagement and callous unemotional traits configurations in adolescents with disruptive behavior disorder: a person-oriented approach. Psychiatry Res. 2017;258:591-593. doi:10.1016/j.psychres.2017.08.043

48. Sijtsema JJ, Garofalo C, Jansen K, Klimstra TA. Disengaging from evil: longitudinal associations between the dark triad, moral disengagement, and antisocial behavior in adolescence. J Abnorm Child Psychol. 2019;47:1-15.

49. Jonason PK, Webster GD. The dirty dozen: a concise measure of the Dark Triad. Psychol Assess. 2010;22:420-432. doi:10.1037/a0019265

50. Walters GD, DeLisi M. Psychopathy and violence: does antisocial cognition mediate the relationship between the PCL: YV factor scores and violent offending? Law Hum Behav. 2015;39(4):35 0-359. doi: $10.1037 / \mathrm{hb} 0000123$

51. Chandler M, Moran T. Psychopathy and moral development: a comparative study of delinquent and nondelinquent youth. Dev Psychopathol. 1990;2(3):227-246. doi:10.1017/S0954579400000742

52. Lorber CM, Hughes TL, Miller JA, Crothers LM, Martin E. Callous and unemotional traits and social cognitive processes in a sample of community-based aggressive youth. Int $J$ Offender Ther Comp Criminol. 2011;55(8):1291-1307. doi:10.1177/0306624X11386012

53. Thornberg R, Birberg Thornberg U, Alamaa R, Daud N. Children's conceptions of bullying and repeated conventional transgressions: moral, conventional, structuring, and personal-choice reasoning. Educ Psychol. 2016;36:95-111. doi:10.1080/01443410.2014.915929

54. Van Leeuwen N, Rodgers RF, Gibbs JC, Chabrol H. Callousunemotional traits and antisocial behavior among adolescents: the role of self-serving cognitions. J Abnorm Child Psychol. 2014;42 (2):229-237. doi:10.1007/s10802-013-9779-z

55. Bandura A, Barbaranelli C, Caprara GV, Pastorelli C. Mechanisms of moral disengagement in the exercise of moral agency. J Pers Soc Psychol. 1996;71:364-371. doi:10.1037/0022-3514.71.2.364

56. Andershed HA, Kerr M, Stattin H, Levander S. Psychopathic traits in non-referred youths: a new assessment tool. In: Blaauw E, Sheridan L, editors. Psychopaths: Current International. Vol. 2002. Elsevier; 2002:131-158.

57. van Baardewijk Y, Andershed H, Stegge H, Nilsson KW, Scholte E, Vermeiren R. Development and tests of short versions of the youth psychopathic traits inventory and the youth psychopathic traits inventory-child version. Eur J Psychol Assess. 2010;26:122-128. doi: $10.1027 / 1015-5759 / \mathrm{a} 000017$

58. Lahey BB, Applegate B, Chronis AM, et al. Psychometric characteristics of a measure of emotional dispositions developed to test a developmental propensity model of conduct disorder. J Clin Child Adolesc Psychol. 2008;37(4):794-807. doi:10.1080/15374410802359635

59. Frick PJ, Hare RD. Antisocial Process Screening Device. Toronto: Multi-Health Systems; 2001.

60. Frick PJ, Cornell AH, Barry CT, Bodin SD, Dane HE. Callousunemotional traits and conduct problems in the prediction of conduct problem severity, aggression, and self-report of delinquency. J Abnorm Child Psychol. 2003;31(4):457-470. doi:10.1023/A:10238 99703866

61. Forth AE, Kosson DS, Hare RD. Hare Psychopathy Checklist: Youth Version. Toronto: Multi-Health Systems; 2003.

62. Perry DG, Perry LC, Rasmussen P. Cognitive social learning mediators of aggression. Child Dev. 1986;57(3):700-711. doi:10.2307/ 1130347

63. Boldizar JP, Perry DG, Perry LC. Outcome values and aggression. Child Dev. 1989;60(3):571-579. doi:10.2307/1130723

64. Davis MH. Measuring individual differences in empathy: evidence for a multidimensional approach. J Pers Soc Psychol. 1983;44(1):11 3-126. doi:10.1037/0022-3514.44.1.113

65. Barriga AQ, Morrison EM, Liau AK, Gibbs JC. Moral cognition: explaining the gender difference in antisocial behavior. Merrill Palmer Q (Wayne State Univ Press). 2001;47(4):532-562. doi:10.13 53/mpq.2001.0020 
66. Little TD, Henrich CC, Jones SM, Hawley PH. Disentangling the "whys" from the "whats" of aggressive behaviour. Int J Behav Dev. 2003;27(2):122-133. doi:10.1080/01650250244000128

67. Kretschmer T, Sentse M, Dijkstra J, Veenstra R. The interplay between peer rejection and acceptance in preadolescence and early adolescence, serotonin transporter gene, and antisocial behavior in late adolescence: the TRAILS study. Merrill Palmer $Q$ (Wayne State Univ Press). 2014;60:193-216. doi:10.13110/merrpalmquar1982.60.2.0193

68. Björkqvist K, Lagerspetz KM, Kaukiainen A. Do girls manipulate and boys fight? Developmental trends in regard to direct and indirect aggression. Aggress Behav. 1992;18(2):117-127. doi:10.1002/10982337(1992)18:2<117::AID-AB2480180205>3.0.CO;2-3

69. Elliott DS, Ageton SS, Huizinga D. Explaining Delinquency and Drug Use. Behavioral Research Inst; 1982.

70. Le Blanc M, Fréchette M. Male Offending from Latency to Adulthood. New York: Springer; 1989.

71. Blair R. A cognitive developmental approach to morality: investigating the psychopath. Cognition. 1995;57(1):1-29. doi:10.1016/00100277(95)00676-P

72. Bandura A. Social Foundations of Thought and Action. Englewood Cliffs: Prentice Hall; 1986.

73. O'Brien BS, Frick PJ. Reward dominance: associations with anxiety, conduct problems, and psychopathy in children. J Abnorm Child Psychol. 1996;24(2):223-240. doi:10.1007/BF01441486

74. Fanti KA, Colins OF, Andershed H, Sikki M. Stability and change in callous-unemotional traits: longitudinal associations with potential individual and contextual risk and protective factors. $\mathrm{Am}$ J Orthopsychiatry. 2017;87(1):62-75. doi:10.1037/ort0000143

75. Ballarotto G, Volpi B, Marzilli E, Tambelli R. Adolescent Internet abuse: a study on the role of attachment to parents and peers in a large community sample. Biomed Res Int. 2018;2018:ID 5769250.
76. Tafà M, Cimino S, Ballarotto G, Bracaglia F, Bottone C, Cerniglia L. Female adolescents with eating disorders, parental psychopathological risk and family functioning. J Child Fam Stud. 2017;26(1):28-39. doi:10.1007/s10826-016-0531-5

77. Cerniglia L, Cimino S, Tafà M, Marzilli E, Ballarotto G, Bracaglia F. Family profiles in eating disorders: family functioning and psychopathology. Psychol Res Behav Manag. 2017;10:305. doi:10.21 47/PRBM.S145463

78. Barriga AQ, Gibbs JC. Measuring cognitive distortion in antisocial youth: development and preliminary validation of the "how I think" questionnaire. Aggressive Behav. 1996;22(5):333-343. doi:10.1002/ (ISSN)1098-2337

79. Ribeaud D, Eisner M. Are moral disengagement, neutralization techniques, and self-serving cognitive distortions the same? Developing a unified scale of moral neutralization of aggression. Int $J$ Conf Violence. 2010;4(2):298-315.

80. Sykes GM, Matza D. Techniques of neutralization: a theory of delinquency. Am Sociol Rev. 1957;22(6):664-670. doi:10.2307/2089 195

81. Gibbs JC, Potter GB, Goldstein AP. The EQUIP Program: Teaching Youth to Think and Act Responsibly Through a Peer-Helping Approach. Research Press; 1995.

82. Pisano S, Muratori P, Gorga C, et al. Conduct disorders and psychopathy in children and adolescents: aetiology, clinical presentation and treatment strategies of callous-unemotional traits. Ital $J$ Pediatr. 2017;43(1):84. doi:10.1186/s13052-017-0404-6

83. Paciello M, Muratori P, Ruglioni L, et al. Personal values and moral disengagement promote aggressive and rule-breaking behaviours in adolescents with disruptive behaviour disorders: a pilot study. Int J Offender Ther Comp Criminol. 2017;61(1):46-63. doi:10.11 77/0306624X15589593
Adolescent Health, Medicine and Therapeutics

\section{Publish your work in this journal}

Adolescent Health, Medicine and Therapeutics is an international, peer-reviewed, open access journal focusing on health, pathology, and treatment issues specific to the adolescent age group. All aspects of health maintenance, preventative measures and disease treatment interventions are addressed within the journal and practitioners from all disciplines are invited to submit their work as well as healthcare researchers and patient support groups. The manuscript management system is completely online and includes a very quick and fair peerreview system. Visit http://www.dovepress.com/testimonials.php to read real quotes from published authors. 